

\section{Sumário}

O USO DE BOTS SOCIAIS COMO AMEAÇA À DEMOCRACIA .............................................................13

Mateus de Oliveira Fornasier

In Memoriam: The Republican Form and the Separation-of-Powers Among the Four

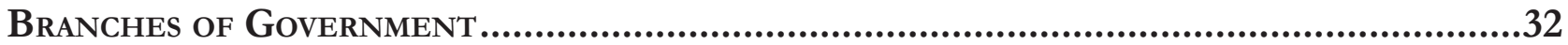

Farris Lee Francis

TODOS E CADA UM DE NÓs: O INTERESSE PÚBLICO COMO CRITÉRIO DE DESENVOLVIMENTO HUMANO

Mártin Haeberlin e Flávio Comim

FACTORES DERIVAdos DE LA POBREZA MULTIDIMENSIONAL QUE AFECTAN LA USABILIDAD DEL e-gobierno en México

Oscar Yahevh Carrera Mora, Luis Fernando Villafuerte e Saulo Sinforoso Martínez

¿Qué ha PASAdo CON Los PRINCIPIOS DE Universalidad, Solidaridad y EFICIENCIA DEL Sistema General de Seguridad Social en Salud de Colombia?

David Mendieta e Carmen Elena

CHANGING THE BENCH FOR A HANDSHAKE: LITIGATION, ADMINISTRATIVE RESOLUTION AND MEDIATION IN FREEDOM OF INFORMATION COMPLAINTS IN CHILE

Pablo Contreras

A evolução identitária da Controladoria-Geral da União: polifonia e decisões em POLÍTICAS DE TRANSPARÊNCIA E ACESSO À INFORMAÇÃO

Érica Bezerra Queiroz Ribeiro e Bruno Amaral Machado

As RAÍZES CRISTÃS DO PRINCÍPIO JURÍDICO DA FRATERNIDADE E AS CRISES MIGRATÓRIAS DO TERCEIRO MILÊNIO.

Maria Celeste Cordeiro Leite dos Santos e Marilene Araujo

JUDICIALIZAÇÃo DESCENTRALIZADA E INDIVIDUALIZADA DA POLÍTICA: MUDANÇAS NAS REGRAS DE tramitação de Medidas Provisórias a partir da Emenda Constitucional 32 155 Leandro Molhano Ribeiro e Mariana Novotny Muniz

O PAPEL DO CNJ DIANTE DO RECONHECIMENTO DO ESTADO DE COISAS INCONSTITUCIONAL DO SISTEMA CARCERÁRIO BRASILEIRO NA PERSPECTIVA DO ATIVISMO DIALÓGICO. 176 Ana Paula Kosak e Estefânia Maria de Queiroz Barboza 
Efeitos do Programa Mais Médicos (PMM) nos resultados da Atenção Básica À SAÚDE.

Alex dos Santos Macedo e Marco Aurélio Marques Ferreira

OrÇamento para os direitos das CRianÇas E adolescentes EM CuRitiba: Plano E EXECUÇÃO

Karoline Strapasson Jambersi e Antonio Gonçalves de Oliveira

A Capacidade do Estado frente a gestão de riscos e desastres após a Política Nacional de Proteção e Defesa Civil (Lei 12.608/2012) .............................................245

Larissa Maria da Silva Ferentz e Carlos Mello Garcias

REFunCIONALIZAÇÃo da PENA DE PRISÃo: ABORDAGEM ACERCA DA ALIENAÇÃo DO TRABALHO

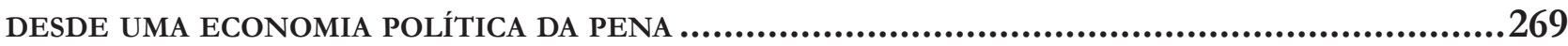
Jackson da Silva Leal

LA CONSTITUCIONALIZACIÓN DEL DERECHO A DEFENSA JURIDICA DE LAS VICTIMAS EN CHILE 286 Marcela Peredo Rojas

COLABORAÇÃo PREMIADA E SELETIVIDADE DO SISTEMA PENAL: PROBLEMATIZAÇõES ACERCA DA UTILIZAÇÃo de aCordos Na Operação LaVa Jato

Maiquel Ângelo Dezordi Wermuth e Maurício Habckost Dalla Zen

Poder, MASCULINIDAde E PARTICIPAÇão EM FaCções CRIMINOSAS A PARTIR DE RELATOS ADOLESCENTES PRIVADOS DE LIBERDADE PELA PRÁTICA DE ATOS INFRACIONAIS

Jailson Alves Nogueira, Ramon Rebouças Nolasco de Oliveira, Lauro Gurgel de Brito e Veruska Sayonara de Góis

MobILIZAÇÃo JURÍDICA E O DIREITO AO ABORTO NO BRASIL: A EVOLUÇão ARGUMENTATIVA NAS RESPECTIVAS AÇÕES DE CONTROLE CONCENTRADO DE CONSTITUCIONALIDADE .355

Fabiano Hartmann Peixoto e Thales Alessandro Dias Pereira 


\title{
Todos e cada um de nós: o interesse público como critério de desenvolvimento humano*
}

\author{
All and each of us: public interest as human \\ development criteria
}

\author{
Mártin Haeberlin** \\ Flávio Comim***
}

\section{Resumo}

O presente artigo busca aproximar interesse público e desenvolvimento humano. Partindo da hipótese de que o interesse público, considerado desde uma abordagem abrangente, é um critério de desenvolvimento humano, aproxima-se o elemento jurídico do interesse público, relacionado à realização de direitos humanos e liberdades básicas, com a Economia do Desenvolvimento, expandindo-se assim o campo de pesquisa para a fundação conceitual elementar da chamada "Capability Approach". Após assinalar que o interesse público impõe um senso de vida em comum baseado em valores coletivos e relacionado a um plexo de sentimentos morais que fazem parte da estrutura das sociedades ("comumnidade"), sustenta-se que esse entendimento deve dirigir tanto ações governamentais como ações humanas. A demonstração da hipótese de trabalho, realizada por pesquisa exploratória de caráter bibliográfico, comporta uma sugestão de leitura do interesse público vinculado ao desenvolvimento humano em três níveis. Para cada nível, demonstram-se algumas métricas usuais de desenvolvimento humano encontradas na literatura. Todavia, diante do acréscimo do terceiro nível, conclui-se pela necessidade de desenhar uma métrica alternativa (que evolua as concepções usuais), em que as equações que compõem o desenvolvimento humano incluam o interesse público, o que é realizado, de modo especulativo, com dados colhidos de países da América Latina.

Palavras-chave: Desenvolvimento Humano. Interesse Público. Capability Approach. Políticas Públicas. América Latina.

\section{Abstract}

This article seeks to approximate public interest and human development. Under the assumption that public interest, considered from a comprehensive approach, is a criterion of human development, it brings closer the legal understanding of public interest, related to the effectiveness of human rights and basic freedoms, with Development Economics, enlarging the field of research to the elementary conceptual foundation of the so-called "Capability Approach". After pointing out that public interest imposes a common sense of life based on collective values and related to a plexus of moral feelings that are part of the structure of societies ("publicness"), it is 
argued that this understanding should rule governmental and human actions. The demonstration of the working hypothesis, performed by exploratory bibliographic research, involves a reading suggestion of public interest linked to human development in three levels. For each of them, the analysis of usual human development metrics is provided. However, considering the addition of a third level, it is concluded that is necessary to draw an alternative metric (which evolves the usual conceptions) where the equations that compose human development include public interest, which is carried out speculatively with data collected from Latin American countries.

Keywords: Human Development. Public Interest. Capability Approach. Public Policies. Latin America.

\section{Introdução}

Em um momento-chave da história da civilização, há cerca de seis séculos antes de Cristo, testemunhou-se uma evolução gradual das comunidades históricas no sentido da substituição de crenças religiosas pela formulação de uma racionalidade política. Criava-se o ambiente para a reflexão sobre aquilo que as pessoas compartilhavam como objetivos, formando uma noção secular, mesmo que incipiente, de "bem comum", ou "interesse público", base para a criação das sociedades modernas.

Daquele momento ao presente, a noção foi objeto de reflexão em diversas áreas, em especial na Filosofia e na Ciência Política. Não obstante, é notável que a tradição jurídica continental tende a conceber o interesse público tratando-o como um conceito autóctone do Direito. Fala-se, pois, de duas abordagens distintas: uma abordagem estrita, em que o interesse público é apenas um desenvolvimento jurídico, relacionado à realização de direitos humanos e liberdades básicas; e uma abordagem abrangente, na qual se acresce ao desenvolvimento jurídico a perspectiva do desenvolvimento humano.

Partindo-se do pressuposto de que a abordagem abrangente deve ser adotada, em razão da insuficiência da abordagem estrita, verifica-se uma vocação do interesse público em fazer evoluir o Estado na direção de suas finalidades, conquanto coincidentes com as finalidades dos seus cidadãos, uma vez que a pergunta pelo interesse público é uma pergunta pelos meios adequados e suficientes para alcançar fins.

Essa perspectiva relaciona Direito e Economia, assumindo os princípios e pressupostos da chamada "Capability Approach", os quais fundamentam os objetivos e a metodologia de acompanhamento expressos primeiramente no âmbito do Relatório de Desenvolvimento Humano de 2010. E, dessa interlocução, proposta desde a abordagem abrangente, propõe-se, como hipótese de trabalho, que o próprio interesse público é um componente essencial para a verificação do desenvolvimento humano.

A partir de pesquisa exploratória de caráter bibliográfico, busca-se, assim, demonstrar a hipótese (analisando a conexão entre interesse público e desenvolvimento humano) do seguinte modo: primeiramente, são expostos alguns pressupostos e conceitos operacionais essenciais da hipótese de trabalho; posteriormente, são analisadas as duas abordagens do interesse público; na sequência, demonstra-se a importância da noção de comumnidade para a definição de interesse público; por fim, apresenta-se, como aproximação empírica da hipótese, uma métrica de comumnidade, sugerindo-se análise desta juntamente ao Índice de Desenvolvimento Humano (IDH) e outros índices consagrados na literatura. 


\section{Da comumnidade ao conceito de interesse público: pressupostos e conceitos operacionais da hipótese de trabalho}

Lê-se, em Fustel de Coulanges, uma mudança revolucionária na história que passa, às vezes, despercebida: a construção das sociedades modernas originou-se de uma substituição das crenças religiosas, como princípio de governo, pela "crença" no interesse públicoํ. A mudança foi revolucionária, pois dela viu-se originar uma racionalidade política calcada na perspectiva de "razão do Estado", base para o florescimento cultural nas cidades. Criava-se o ambiente para a reflexão sobre aquilo que é o bem para as pessoas e sobre os fundamentos que lhes unem sob um governo comum. O que chamamos interesse público (ou bem comum $^{3}$ ) não surgiu ipso facto, portanto, com a noção de cidade-Estado, mas quando essa noção passou a ser refletida.

$\mathrm{O}$ ato de se associar, instaurando uma sociedade em um bem comum, revela uma compreensão daquilo que se pode chamar comumnidade. ${ }^{4}$ Isso é, um senso de vida em comum sustentado em valores coletivos e relacionado a um plexo de sentimentos morais que fazem parte da estrutura das sociedades.

Um bem que se quer comum (ou uma comunidade que visa à comumnidade) é um bem que se modula no binômio relacionamento-experiência do "eu-tu" em um determinado tempo e espaço ${ }^{5}$. A adjetivação do substantivo bem, em bem comum, é a conexão intersubjetiva em torno de um objeto da experiência. É o ato de associação em que todos os associados visam a um mesmo (comum) algo (bem). E todos os associados têm a real possibilidade de acessar esse algo, posto que, de sua etimologia, sabe-se comum (communis) o "acessível a todos"

Proclamada a identidade das noções de interesse público e bem comum — e, portanto, considerado que o interesse público lida com a busca por algo que os associados de uma comunidade visam e que deve ser acessível a todos - , notamos, como afirmado na introdução, que uma abordagem estrita de interesse público, que considera apenas o seu sentido jurídico, é insuficiente. Em seu lugar, deve ser adotada uma abordagem abrangente, na qual se acresce ao desenvolvimento jurídico a perspectiva do desenvolvimento humano. No contexto dessa abordagem, pode-se partir de uma definição de interesse público como "o elemento nuclear

\footnotetext{
COULANGES, Fustel de. La Cité Antique. Paris: Librairie Hachette, 1900. p. 438.

2 FOUCAULT, Michel. Omnes et singulatim: vers une critique de la raison politique. 1994. p. 134-161. Disponível em: http://www. cip-idf.org/article.php3?id_article=4031. Acesso em: 15 dez. 2019.

3 Concorda-se com a tese de que interesse público e bem comum possuem, em essência, mesmo significado, na esteira de autores como Peter Häberle, Walter Schmidt, Josef Isensee e Robert Uerpmann (cf. CALLIESS, Christian. Gemeinwohl in der Europäischen Union: uber den staaten-und verfassungsverbund zum gemeinwohlverbund. In: BRUGGER, Winfried; KIRSTE, Stephan; ANDERHEIDEN, Michael (org.). Gemeinwohl in Deutschland, Europa und der welt. Interdis₹iplinäre Studien zu Recht und Staat, Baden-Baden, n. 24, 2002. p. 176), Maria Sylvia Zanella di Pietro (DI PIETRO, Maria Sylvia Zanella. O Princípio da supremacia do interesse público: sobrevivência diante dos ideais do neoliberalismo. In: DI PIETRO, Maria Sylvia Zanella; RIBEIRO, Carlos Vinícius Alves (coord.). Supremacia do interesse público e outros temas relevantes do direito administrativo. São Paulo: Atlas, 2010. p. 87), José dos Santos Carvalho Filho (CARVALHO FILHO, José dos Santos. Interesse público: verdades e sofismas. In: DI PIETRO, Maria Sylvia Zanella; RIBEIRO, Carlos Vinícius Alves (coord.). Supremacia do interesse público e outros temas relevantes do direito administrativo. São Paulo: Atlas, 2010. p. 73) e Thiago Lima Breus (BREUS, Thiago Lima. Políticas públicas no estado constitucional: problemática da concretização dos direitos fundamentais pela administração pública brasileira contemporânea. Belo Horizonte: Fórum, 2007. p. 132-8), dentre outros.

4 O neologismo "comumnidade" serve para diferenciar esse senso de vida relacional, ausente no substantivo "comunidade", que é o lugar da vida relacional. Esse é sua existência empírica; aquele, a sua existência refletida. Com o termo, buscamos unir o neologismo criado por Mártin Haeberlin (HAEBERLIN, Mártin. Uma teoria do interesse público: fundamentos do estado meritocrático de direito. Porto Alegre: Livraria do Advogado, 2017. p. 44) com o significado de "publicness" formulado, originalmente, por Flávio Comim (COMIM, Flávio Vasconcellos. Publicness and human development. In: 2015 HUMAN DEVELOPMENT AND CAPABILITY ASSOCIATION CONFERENCE, 2015, Washington. Proceedings...Washington: Georgetown University, 2015. p. 13). Essa união confere, a um só tempo, uma proposição de tradução ao termo - sem correspondente perfeito em língua portuguesa - e uma proposição de significado, considerando a base comum entre ambos.

5 BUBER, Martin. Ich und du. Stuttgart: Philip Reclam, 1995.

VERNES, Monique. Les illusions endémiques du bien commum: concept opératoire ou formule rhétorique? In: DELAS, Olivier; DEBLOCK, Christian (org.). Le bien commun comme réponse politique à la mondialisation. Bruxelles: Bruylant, 2003. p. 34.
} 
do Estado que obriga sua ação seja nexo, preferencialmente direto e imediato, do maior empreendimento possível de cada um de nós, sendo a sustentabilidade pressuposta a esse interesse e o fomento de uma cultura fundada na obrigação moral de que o empreendimento do outro seja a cada um de nós maximamente relevante uma medida de sua eficácia." ${ }^{\text {T }}$

Considera-se, pois, como pressuposto, que o interesse público é uma noção que promove a evolução das pessoas por meio de suas organizações políticas (instituições), devendo se assegurar que a finalidade dos Estados nacionais, disposta em seus arcabouços normativos, deve coincidir com os objetivos dos seus cidadãos, em especial com o objetivo da emancipação (autonomia) desses.

Desse pressuposto, fica realçado que a abordagem abrangente do interesse público aqui adotada — a qual assume, como premissa, a possibilidade de concordância entre interesses sociais desde uma interlocução saudável entre instituições e indivíduos — coloca o Direito vis-à-vis à Economia em suas mais distintas escolas. Neste estudo, porém, essa relação é abordada fundamentalmente a partir da perspectiva do Desenvolvimento Humano, assumindo-se os princípios e pressupostos da "Capability Approach" de Mahbub ul $\mathrm{Haq}^{8}$, Streeten ${ }^{9}$, Amartya Sen ${ }^{10}$ e Martha Nussbaum ${ }^{11}$, os quais fundamentam os objetivos e a metodologia de acompanhamento do Desenvolvimento primeiramente expressos no âmbito do Relatório de Desenvolvimento Humano de $2010^{12}$.

\section{Interesse Público: duas abordagens}

Peter Häberle, em texto clássico ${ }^{13}$, preocupara-se com a ideia de um conceito de interesse público do ponto de vista jurídico, analisando o interesse público nas funções legislativa, administrativa e jurisdicional. Propunha ele ${ }^{14}$ a necessidade de uma autonomia prática do trabalho jurídico na orientação do problema para sustentar o significado do "interesse público" especificamente para a interpretação constitucional, descolando dele conjunções políticas, econômicas ou filosóficas. Seu estudo deu o tom para diversos trabalhos jurídicos posteriores, notadamente na doutrina continental (eurocêntrica).

Diferentemente de Häberle, partiremos da premissa de que a noção de interesse público (ou bem comum) é esvaziada quando tratada, apenas, sob seu viés jurídico. Sugere-se, pois, a necessidade de um trabalho interdisciplinar, considerando que a "[a] preocupação em torno do bem comum não se restringe ao direito." ${ }^{15}$ Entendendo, como afirmara Ernst Fraenckel ${ }^{16}$, que o bem comum é um resultado que tem, entre suas causas, forças econômicas, sociais, políticas e ideológicas de uma nação, busca-se o conhecimento de outras ciência, as quais, às vezes, sequer compartilham os mesmos métodos com a dogmática jurídica.

HAEBERLIN, Mártin. Uma teoria do interesse público. Porto Alegre: Livraria do Advogado, 2017. p. 255-256.

HAQ, Mahbub ul. Reflections on buman development. Delhi: Oxford University Press, 1999.

STREETEN, Paul Patrick. Thinking about development. Cambridge: Cambridge University Press, 1995.

10 SEN, Amartya. Development as freedom. Oxford: Oxford University Press, 1999. SEN, Amartya. The idea of justice. Cambridge: Harvard University Press, 2009.

11 NUSSBAUM, Martha. Creating capabilities: the human development approach. Cambridge: The Belnak Press of Harvard University Press, 2011.

12 UNITED NATIONS DEVELOPMENT PROGRAMME. Human development report 2010: the real wealth of nations: pathways to human development. New York: Palgrave Macmillan, 2010.

13 HÄEBERLE, Peter. Öffentliches interesse als juristisches problem: eine analyse von gesetzgebung und rechtsprechung. Berlin: Berliner Wissenschafts-Verlag, 1970.

14 HÄEBERLE, Peter. Öffentliches Interesse als Juristisches Problem: eine analyse von gesetzgebung und rechtsprechung. Berlin: Berliner Wissenschafts-Verlag, 1970. p. 17.

15 ANDERHEIDEN, Michael. Gemeinwobl in republik und union. Tübingen: Mohr Siebeck, 2006. p. 46.

16 Cf. BLANKART, Charles. Gemeinwohl durch direkte und repräsentative Demokratie. In: ARNIM, Hans Herbert von; SOMMERMANN, Karl-Peter (org.). Gemeinwoblgefäbrdung und gemeinwohlsicherung: vorträge und diskussionsbeiträge auf der 71: staatswissenschaftlichen fortbildungstatung. Berlin: Duncker \& Humboldt, 2004. p. 247. 
Falaremos, assim, em duas abordagens sobre o interesse público, uma na qual o interesse público é visto em espectro, apenas, jurídico, outra que lhe acrescenta o espectro humano, onde ele passa a ser pensado aliado a outras ciências, em especial à Economia. Não obstante tenhamos, de pronto, perfilado a segunda, nas linhas que seguem apresentamos, em síntese, uma interpretação de ambas abordagens.

\subsection{A abordagem estrita: interesse público como desenvolvimento jurídico}

A ideia de uma abordagem estrita do interesse público refere-se ao fechamento da apresentação de problemas e solucõoes sobre o tema em desenvolvimentos com matriz na dogmática jurídica. Mesmo reconhecendo modos distintos de operar esses problemas e soluções, pode-se entender o interesse público, nesse sentido, como a busca por um "cânon de valores" pré-constitucionais (anteriores a uma Constituição positivada), os quais criam, na expressão de Ronald Dworkin"17, “[...] o esqueleto constitucional de uma sociedade composta por cidadãos iguais e livres".

Em geral, os Estados Democráticos de Direito contemporâneos - e a democracia é um pressuposto para ambas as abordagens que fazemos - aceitam essa noção de "pré-constitucionalidade" referindo-se a ela como a "Constituição em sentido material", o que fazem, expressa ou tacitamente, substituindo uma teoria da justiça por uma teoria dos direitos fundamentais, aceita hoje com poucas variações de fundo.

Os direitos fundamentais confundem-se, de fato, com a materialidade da Constituição, pois "[n]ão há constitucionalismo sem direitos fundamentais. Tampouco há direitos fundamentais sem a constitucionalidade da ordem material cujo norte leva ao princípio da igualdade, pedestal de todos os valores sociais de justiça." ${ }^{18}$. Sobressai, daí, inerência entre o interesse público e a eficácia dos direitos fundamentais, quer nos direitos de defesa, quer nos direitos prestacionais, nos quais opera seu conteúdo de forma mais incisiva. É neles que os problemas do interesse público, afinal, estão vinculados à distribuição equitativa de bens públicos, desde os mais tangíveis, como saúde e educação, aos mais intangíveis, como as noções de "public framework of thought"19 e de "stability of a society's political culture"

$\mathrm{Na}$ medida em que os direitos fundamentais dimensionam interesses plurais, ao reconhecimento de um conjunto desses direitos, todos com certo pendor de eficácia, está pressuposta "uma questão de princípio"21, em que seus conteúdos constitucionais ganham densidade na colisão entre uns e outros, a ser resolvidos, juridicamente, por procedimentos de ponderação, uma vez que "ele [o interesse público] é determinado em situações concretas de decisão, para se saber qual decisão corresponde ao interesse público."22

A pluralidade de interesses - e, por consequência, de direitos fundamentais — é, pois, uma característica própria do Direito Público nos Estados Sociais contemporâneos. Desde sempre, eles se formam a partir de interesses individuais, e os interesses individuais tornam-se grupos plurais, e estes, por sua vez, consoante Karl Loewenstein ${ }^{23}$, “[...] são componentes orgânicos da biologia da sociedade civil.”

A diversidade produz efeitos jurídicos. A experiência de um conflito de liberdades requer um catálogo de direitos fundamentais, não se podendo mais imprimir, como outrora, uma imagem de alta resolução, fácil, na qual o Direito Privado consagrava o princípio de autonomia e o Direito Público o Princípio do Interesse Público. Este, juridicamente falando, passa a ser melhor entendido como um ponto focal que diagrama

DWORKIN, Ronald. Unenumerated rights: wheter and how roe should be overruled. The University of Chicago Law Review, Chicago, v. 59, n. 1, p. 381-432, 1992. p. 382

18 BONAVIDES, Paulo. Curso de direito constitucional. 14. ed. São Paulo: Malheiros, 2004. p. 601.

19 SEN, Amartya. The idea of justice. Cambridge: Harvard University Press, 2009. p. 134.

20 NUSSBAUM, Martha. Political emotions: why love matters for justice. Cambridge: the Belnak Press of Harvard University Press, 2013.

21 DWORKIN, Ronald. A matter of principle. New York: Oxford University Press, 1985.

22 UERPMANN, Robert. Das öffentliche interesse: seine bedeutung als tatbestandsmerkmal und als dogmatischer begriff. Tübingen: Mohr Siebeck, 1999. p. 289.

23 LOEWENSTEIN, Karl. Verfassungslehre. Tradução de Rüdiger Boerner. Tübingen: Mohr Siebeck, 1959. p. 371. 
multifacetadas ações estatais e privadas, consubstanciadas nos mais diversos princípios requerendo as mais diversas ponderações (em atos legislativos, administrativos e jurisdicionais). Nas plurais sociedades democráticas contemporâneas, a colisão de direitos fundamentais está presente em cada ação estatal tendente à realização das suas finalidades.

O interesse público, nessa visão estrita (enquanto desenvolvimento jurídico), encontra-se, por conseguinte, na colisão dos direitos fundamentais. Ínsito à dimensão objetiva desses, vê-se revelado no núcleo das opções constitucionais com base no "[..] conjunto de valores objetivos básicos e fins diretivos da ação positiva dos poderes públicos [...]"24. Está na ponderação de interesses da política legislativa (no plano legislativo) e das políticas públicas (no plano administrativo). É a ponderação que confere ao ato estatal presunção de legitimidade, dando-se importância ao significado do texto constitucional em conformidade àquela dimensão objetiva.

Trata-se essa abordagem de uma justiça constitucionalizada cujo núcleo é o interesse público. Mas a teoria da justiça está pressuposta na Constituição. Esta é o seu "marco zero", por assim dizer. O interesse público cria-se na verossimilhança (constatável ou não) de que o pressuposto de justiça constitucional é, de fato, uma constitucionalização da justiça substantiva pré-constitucional. Conhecer o pressuposto não é papel dessa abordagem.

\subsection{A abordagem abrangente: interesse público como desenvolvimento jurídico e humano}

A ideia de uma abordagem abrangente do interesse público refere-se à abertura da apresentação de problemas e solucõoes sobre o tema desde desenvolvimentos outros, para além da dogmática jurídica. Entende-se que o interesse público, a partir do qual se constrói uma teoria da justiça, não é reduzido a essa Teoria da Justiça. Juntamente a ela, o interesse público prescreve um estado de coisas, de modo prospectivo, isso é, para realização futura. Essa ordem de coisas abrange diversas dimensões, como a política, social, cultural e econômica. São, pois, próprias do humano, ou humanísticas.

Nessa abordagem abrangente passa-se a trabalhar com o interesse público como capaz de traduzir algo aproximado àquilo que Georg Jellinek ${ }^{25}$ chamara "öffentliche Meinung”, ao dizer que "[a] totalidade das contemplações morais, religiosas, literárias, econômicas gera à 'mentalidade pública’ um círculo menor ou maior.”

Não apenas as sociedades, mas os indivíduos terão seus "círculos" maiores ou menores. Deve-se ter ciência de que a expansão desses círculos pessoais geram, sempre, um ganho igual ou maior para a "öffentliche Meinung". A promoção — mais do que o mero respeito — do interesse de cada um é interesse de todos, pois todos creditam-se pela expansão do círculo. ${ }^{26}$ Assim ocorre, por exemplo, com os alunos de um professor que recebe uma formação diferenciada, ou quando centros de pesquisa concentram pessoas altamente qualificadas, o que implica, geralmente, resultados significativos do grupo e também no crescimento individual de seus membros, diante da influência positiva de uns em relação aos outros.

É papel do interesse público a expansão desses círculos pessoais (e, pois, da “öffentliche Meinung”). O interesse público deve ser lido como um fomentador para prospectar infinitos futuros, desenhando-os no horizonte de cada um. É essa "expansão do círculo", em ordem com a evolução do Estado, que dita o espaço da atuação estatal. Pensar no interesse público é, pois, pensar que todo ente tende a sua evolução, não sendo diferente com o Estado, que evolui à medida da evolução de seus concidadãos. O Estado deve ser pensado, assim, em sua utilidade dogmática, proporcional à sua aptidão para gerar causalidade (validade, eficácia, efetividade e execução) entre as suas ações e a ordem material de coisas que produzir a sua gente.

\footnotetext{
24 SARLET, Ingo Wolfgang. Teoria geral dos direitos fundamentais. In: SARLET, Ingo Wolfgang; MARINONI, Luiz Guilherme; MITIDIERO, Daniel. Curso de direito constitucional. 3. ed. São Paulo: Revista dos Tribunais, 2014. p. 310.

25 JELLINEK, Georg. Allgemeine staatslehre. 3. ed. Berlin: O. Häring, 2014. p. 102.

26 Sobre essa asserção, vide ENGEL, Christoph; ROCKENBACH, Betinna. We are not alone: the impact of externalities on public good provision. 2011. Disponível em: http://ssrn.com/abstract=1463259. Acesso em: 15 dez. 2019.
} 
Pode-se dizer que, enquanto a Teoria da Justiça é central para a abordagem estrita do interesse público, para a abordagem abrangente a centralidade está na teoria do desenvolvimento bumano.

É na Economia que se arregimentam as melhores explicações que conhecemos sobre o tema, de modo que esse campo de estudos merece especial atenção, conquanto se tenha presente a advertência: "[a] questão fundamental é a de saber se o ser humano está a serviço da economia ou a economia a serviço do ser humano." ${ }^{27}$ Quando se fazem perguntas sobre o bem comum, ademais, "[p]ara as respostas são necessárias considerações derivadas da economia." 28

Pode-se lidar com o desenvolvimento econômico desde uma perspectiva de aumento da produção, do consumo, do produto interno ou, mesmo, desde um ponto de vista welfarista, em que se desloca o eixo da produção da riqueza para o de sua distribuição. ${ }^{29}$ Uma vez que lidamos com uma perspectiva de desenvolvimento humano, essas visões tradicionais devem ser também alargadas. Ainda que, nessa última ideia, calcada no "bem-estar", possamos encontrar um importante elemento para favorecer necessidades básicas dos indivíduos, devemos ter em mente a crítica de Amartya $\operatorname{Sen}^{30}$ : essas concepções, ao adotar o conceito de utilidade, realizam avaliações de bem-estar relacionadas à eficiência na distribuição de bens onde consideram os indivíduos meras "unidades básicas", o que, segundo ele, faz esse pensamento econômico distanciar-se da ética.

O trabalho de Amartya Sen, a partir desse pressuposto crítico, mostra-se uma base importante daquilo que entendemos como abordagem abrangente do interesse público. Isso porque, buscando reestreitar a ética e a economia, propõe ele a substituição do critério de utilidade pela noção de liberdades substantivas, isso é, a autonomia de alguém escolher uma vida que se tem razão para valorizar. A liberdade assume o papel inclusivo de fazer com que as pessoas possam ter reais condições de fazer suas escolhas. Nos termos aqui utilizados, produz-se uma “expansão dos círculos pessoais". Nas palavras de Sen ${ }^{31}$ :

[...] a expansão da liberdade é vista, nesta abordagem, como o fim principal e como o meio principal do desenvolvimento. $\mathrm{O}$ desenvolvimento consiste em remover vários tipos de privação de liberdades que deixam pessoas com poucas escolhas e poucas oportunidades de exercer sua capacidade de agir de acordo com a razão. A remoção de privação de liberdades, arguimos, é constitutiva do desenvolvimento. Todavia, para um pleno entendimento da conexão entre desenvolvimento e liberdade temos de ir além desse reconhecimento básico, por mais crucial que ele seja. A importância intrínseca da liberdade humana, em geral, como o objetivo proeminente do desenvolvimento, é fortemente suplementada pela efetividade instrumental de liberdades específicas para promover a liberdade de outros tipos.

O desenvolvimento, desde essa visão, encontra na liberdade um papel constitutivo (fim) e instrumental (meio). E, mais importante, não se limita às questões tradicionais do domínio econômico de produção e distribuição. Dirigem-se ao efeito das ações políticas nas liberdades pessoais e na qualidade de vida das pessoas.

Amartya Sen é expoente de um pensamento econômico contemporâneo que atribui ao desenvolvimento um novo papel transformador, que reorganiza e democratiza o mercado. Esse papel seguiria, na visão de Roberto Mangabeira Unger ${ }^{32}$, duas proposições: primeira, a de oferecer "[...] uma ascensão em direção à experiência da posse-de-si e da auto-realização, que tem exercido um papel tão central no pensamento

\footnotetext{
27 LEUPRECHT, Peter. Idéologie pan-économique et bien commun. In: DELAS, Olivier; DEBLOCK, Christian (org.). Le bien commun comme réponse politique à la mondialisation. Bruxelles: Bruylant, 2003. p. 5.

28 ANDERHEIDEN, Michael. Ökonomik, gemeinwohl und verfassungsrecht. In: BUNGENBERG, Marc (org.). Recht und ökonomik. München: C.H. Beck, 2004. p. 113.

29 Exemplo desse ponto de vista encontramos em Arthur Pigou (PIGOU, Arthur. The economics of welfare. 4. ed. London: Transaction, 2002), que inicia o seu The Economics of Welfare sob o pressuposto de que o principal motivo do estudo da economia é ajudar o desenvolvimento social, e endereça o seu estudo às formas que tornam possíveis aos governos controlar o jogo das forças econômicas de modo a produzir o bem-estar econômico e, através dele, o bem-estar total dos cidadãos como um todo.

30 SEN, Amartya. On ethics and economics. Gateshead: Blackwell, 1988.

31 SEN, Amartya. Development as freedom. Oxford: Oxford University Press, 1999. p. xii.

32 UNGER, Roberto Mangabeira. The left alternative. London: Verso, 2009.
} 
cristão, romântico e liberal, para as ideologias seculares de emancipação." 33 ; segunda, a de criar alternativas institucionais aos modelos dominantes e antagônicos (como capitalismo e socialismo), em direção a um pensamento programático sustentado no princípio de que “[...] todos devem compartilhar, de algum modo e em algum momento, a responsabilidade de cuidar de pessoas fora de sua própria família." 34

Evidencia-se, com isso, uma importante noção de senso de vida em comum (comumnidade) que se relaciona ao interesse público, uma vez que, para a "expansão do círculo", exige-se um comprometimento com o bem do outro. Mais do que solidariedade, mostra-se uma consciência de solidariedade, onde a realização de cada um subsiste com a realização dos outros. Ver o outro no exercício de suas realizações, numa sociedade em que haja comumnidade, passa ser uma imagem do sublime. Como aparece na frase de Goethe, citada por Unger ${ }^{35}$ : "contra os talentos superiores de outra pessoa não há defesa; há amor." O interesse público alarga a eficácia do esqueleto de direitos e liberdades básicas. Mas, conceitual e pragmaticamente, ele deve incluir uma visão de prosperidade onde ver o outro no exercício de sua realização importa tanto quanto a eficácia desse esqueleto.

\section{Interesse Público e a Importância da Noção de Comumnidade para sua Definição}

A formulação de uma definição de interesse público, na linha do exposto na seção anterior, deve comportar a abordagem ampla, apta a considerar o desenvolvimento jurídico (uma máxima realização dos direitos fundamentais, ou, dito de outro modo, uma menor colisão desses direitos) e o desenvolvimento humano (uma máxima realização das pessoas de acordo com seus objetivos).

\subsection{A definição do interesse público e as ações do Estado}

Pensar o interesse público desde uma abordagem abrangente importa pensar o Estado e suas ações também desde uma abordagem abrangente. Esse mandamento está bem traduzido no art. $5^{\circ}$, inciso II, da Constituição da Confederação Suíça: "A atividade do Estado deve ser exercida de acordo com o interesse público e proporcional aos fins perseguidos. "Seguir o mandamento, na ideia de uma "boa administração pública" ${ }^{\prime 36}$, passa, assim, por reduzir a cadeia de desdobramentos dos atos estatais, aproximando o nexo de causalidade entre a ação do Estado e a sua efetiva contribuição para os resultados finais pretendidos, constantes de finalidades constitucionais, na medida em que "o efetivo respeito, proteção e promoção dos direitos fundamentais depende sobretudo dos resultados concretos de políticas públicas existentes acerca desses direitos" ${ }^{\prime 37}$.

Nesse mesmo sentido, defende Batista Junior o dever da Administração Pública em assegurar o bem-estar dos indivíduos e a dignidade da pessoa humana, estando por isso "sujeita a um dever de eficiência (pública), que se traduz na necessidade de persecução otimizada do bem comum, contando com recursos

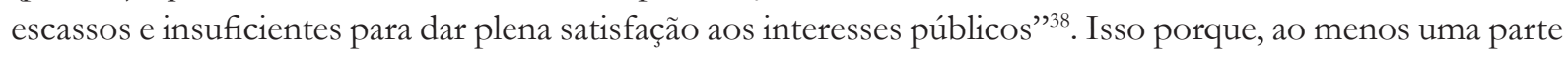
da pergunta pelo interesse público compreende a noção de meios adequados e suficientes para alcançar fins.

\footnotetext{
UNGER, Roberto Mangabeira. The left alternative. London: Verso, 2009. p. vii-viii.

UNGER, Roberto Mangabeira. The left alternative. London: Verso, 2009. p. x.

UNGER, Roberto Mangabeira. The left alternative. London: Verso, 2009. p. 160.

36 FREITAS, Juarez. Discricionariedade administrativa e o direito fundamental à boa administração pública. 2. ed. São Paulo: Malheiros, 2009. p. 22.

37 BARCELLOS, Ana Paula de. Políticas públicas e o dever de monitoramento: "levando os direitos a sério". Revista Brasileira de Políticas Públicas, Brasília, v. 8, n. 2, p. 251-265, ago. 2018. p. 252.

38 BATISTA JUNIOR, Onofre Alves. O estado democrático de direito pós-providência brasileiro em busca da eficiência pública e de uma administração pública mais democrática. Revista Brasileira de Estudos Políticos, Belo Horizonte, v. 98, p. 119-158, 2008. p. 153.
} 
Outra parte da pergunta pelo interesse público, porém, refere-se, diretamente, aos fins. E não apenas aos fins constitucionais, mas, na linha do exposto, aos pré-constitucionais, em relação ao respeito ao desenvolvimento humano. Fala-se na ideia de evolução do Estado pela realização das pessoas, em sua emancipação.

Essa segunda direção da pergunta permite elar o elemento jurídico ao humano, uma vez que a emancipação é tendente também à máxima realização dos direitos fundamentais, com a vantagem de que, enquanto as finalidades constitucionais positivadas não possuem vocação para a universalidade, o sentido da emancipação possui. Esse papel da emancipação em maximizar a realização de direitos e liberdades, reduzindo a colisão dos direitos fundamentais, pode ser demonstrado logicamente em dois postulados: i) a evolução do Estado é inversamente proporcional à colisão de direitos fundamentais, uma vez que a maior emancipação induz contingentemente à realização de direitos; e ii) uma ideia ótima de interesse público busca a maximização da evolução do Estado e a minimização da colisão.

Isso nos daria a visão de uma função, na qual o interesse público não se apresentaria como uma grandeza, mas como a constante da relação entre aquelas duas outras grandezas: a evolução do Estado e a colisão de direitos fundamentais. A função ficaria assim representada:

\[ E \propto \frac{1}{C D F} e E \propto \frac{1}{C D F} \quad \text { ou } \quad e E=\frac{t p}{C D F} e E=\frac{t p}{C D F} \quad \text { ou } \]
$i p=e E \times C D F$

ip $=$ interesse público eE = evolução do Estado $\mathrm{cDF}=$ colisão de direitos fundamentais

A função parece demonstrar, igualmente, que a pergunta sobre o papel do Estado para a consecução do interesse público (isto é, menos ou mais intervencionista) deveria dar lugar ao entendimento da relação de proporção entre a evolução do Estado, em parâmetros humanos, e a redução das colisões de direitos fundamentais para a persecução das finalidades desse Estado, no plano jurídico. Isso porque a definição de interesse público é produto daquilo que é inversamente proporcional. As variáveis são os elementos (colisão e evolução do Estado).

Tais postulados afastam-se da composição do interesse público; doutrinas políticas ortodoxas que abordam concepções dicotomizantes do bem comum (seja ao privilegiar a liberdade com prejuízo da igualdade, seja ao promover igualdade subtraindo liberdades) em favor de uma diretriz para a atuação do Estado em torno dos desenvolvimentos jurídico e humano. Esses postulados também afastam algumas doutrinas de moralidade (como o individualismo e o utilitarismo), pelo mesmo motivo. Que tipo de doutrinas os postulados não afastam? As que buscarem emancipação humana e, pela consequência lógica sinalada, a diminuição da colisão de direitos fundamentais. Também não se afastam eventuais doutrinas que visarem ao significado de emancipação, sendo, de algum modo, instrumentais àquelas. Um exemplo, talvez o mais evidente, seria a chamada "ética da virtude" 39 , uma concepção de justiça iniciada na ética aristotélica. Para essa concepção, a "[...] justiça envolve o cultivo da virtude e o raciocínio sobre o bem comum." ${ }^{\prime 40}$ De diferentes maneiras pode-se ler esse parâmetro de "cultivo de virtudes", algumas mais e outras menos pluralistas. Em nossa leitura, o cultivo das virtudes, consoante exposto na concepção de abordagem abrangente do interesse público, relaciona-se à celebração do exercício das realizações nossas e alheias.

Em seu favor, essa doutrina de moralidade, ao almejar um "raciocínio sobre o bem comum", coloca em destaque que, para além da atuação do Estado (pessoa jurídica de direito público), há uma importância fundamental sobre a definição do interesse público pela atuação dos sujeitos (as pessoas naturais que o compõe).

39 Sobre o tema, vide, sobretudo, MACINTYRE, Alasdair. After virtue: a study in moral philosophy. 3. ed. Notre Dame: University of Notre Dame, 2007. (especialmente p. 121 e seguintes).

40 SANDEL, Michael. Justice: what's the right thing to do? New York: Farrar, Straus and Giroux, 2010. p. 260. 


\subsection{A definição do interesse público e as ações das pessoas}

Em que pese o desenvolvimento humano não possa ser obtido apenas por meio de normas jurídicas positivadas, é válido observar que a relação entre o interesse público e as ações das pessoas, assim como ocorrera na sua relação com as ações do Estado, também possui uma bela demonstração na Constituição suíça. Lê-se tal relação no art. $6^{\circ}$ daquela Carta: "cada pessoa é responsável por si mesmo e deve envidar seus esforços para lidar com as tarefas do Estado e da sociedade. "

Com efeito, não há solução para uma sociedade na qual os indivíduos transponham unicamente ao Estado a solução dos seus problemas, abdicando da tarefa de lhes solucionar por meio da comumnidade. Deve-se reconhecer "[...] o papel objetivo dos fins subjetivos na totalidade dos acontecimentos" ${ }^{41}$, sufragando as pessoas como responsáveis por si e pelos outros. O sujeito, no exercício da faculdade racional, deve entender a sua relação de poderes e deveres com o meio e, portanto, considerar-se presente, em ação, na "teia da vida" — onde, conforme identificado por Frijof Capra ${ }^{42}$, “[...] todos os seres vivos são membros de comunidades ecológicas ligadas umas às outras numa rede de interdependência” —, a qual deve se fazer sustentável. Não em um discurso romântico de sustentabilidade, mas pela aceitação pragmática, porque de causalidade direta, entre as nossas ações e aquilo que é construído a nossa volta, aprendendo do modo ecológico o modo social de pensar sobre o tema. A sustentabilidade, nesse sentido, trata da "[...] universalização do respeito às condições multidimensionais da vida de qualidade." ${ }^{43}$ A emancipação pessoal, traduzida na realização do empreendimento de cada um, compreende esse "empreendedorismo pessoal" em seu imenso potencial de mudança social.

Não há visão possível (muito menos sustentável) de interesse público enquanto não se fundar uma cultura forte no sentido do nexo entre as ações públicas e privadas para a qual o empreendimento de todos é complementar ao nosso. Usa-se chamar solidariedade esse desígnio, do qual se forma "[...] a disposição de reconhecer o problema de outras pessoas ou grupos de pessoas como um problema próprio." ${ }^{44}$ Entendemos ele como comumnidade. E entendemos que ele, reinterpretando o argumento liberal, é essencial à definição do direito e do interesse público.

No argumento liberal, em seu sentido clássico, está compreendida a necessária separação de esfera das ações da sociedade política e dos indivíduos, sendo que, para o interesse destas àquelas devem ajustar-se, inclusive porque o ajuste seria realizado pelo bem da sociedade política. ${ }^{45} \mathrm{O}$ entendimento, interpretado como uma substituição do Estado pelos mercados, remete ao núcleo da pergunta sobre a fundação do Estado, quando se entende, desde essa visão liberal, que o Estado — justificadamente ou não — surgiu em sacrifício da vida e da propriedade ${ }^{46}$.

Ocorre que uma pergunta que já supõe o Estado como um sacrificador da vida e da propriedade somente possui sentido quando o Estado é, de antemão, entendido equivocadamente em suas finalidades. Em entendimento adequado, o modelo de argumento deve ser virado ao avesso: o agir estatal está para concretizar a vida e a propriedade, na medida em que, em sua finalidade, adota um modelo de justiça (e interesse público) fomentador do empreendimento pessoal de cada um, ao qual todos devem contribuir. A noção de

\footnotetext{
41 JONAS, Hans. O princípio responsabilidade: ensaio de uma ética para a civilização tecnológica. Tradução de Marijiane Lisboa e Luiz Barros Montez. Rio de Janeiro: Contraponto, PUC-Rio, 2010. p. 127.

42 CAPRA, Fritjof. A teia da vida: uma nova compreensão científica dos sistemas vivos. Tradução Newton Roberval Eichemberg. São Paulo: Cultrix, 1996. p. 28.

43 FREITAS, Juarez. Sustentabilidade: direito ao futuro. Belo Horizonte: Fórum, 2011. p. 68.

44 CALLIESS, Christian. Gemeinwohl in der Europäischen Union: Über den staaten-und verfassungsverbund zum gemeinwohlverbund. In: BRUGGER, Winfried; KIRSTE, Stephan; ANDERHEIDEN, Michael (org.). Gemeinwohl in Deutschland, Europa und der Welt. Interdisziplinäre Studien zu Recht und Staat, Baden-Baden, n. 24, 2002. p. 196.

45 Sobre o tema, vide DEWEY, John. Liberalism and social action. New York: Prometheus Book, 2000. O argumento, exposto ao longo do livro, é sintetizado na página 8.

46 HELLER, Hermann. The nature and structure of the state. Cardozo Law Review, New York, v. 18, n. 1, p. 1139-1116, set. 1996. p. 1151.
} 
Estado, mesmo constituída sob com o poder de coerção, somente é sustentável em uma organização que possui, como pressuposto, a garantia de que a coerção realiza finalidades constitucionais justas. Percebe-se que a questão desloca seu eixo do domínio político para a ordem administrativa e jurídica, pois envolve o núcleo das finalidades estatais.

Se é verdade que, por casualidade, a ação individual pode ocasionar bem de todos, é igualmente verdade que essa casualidade há de ser lida como uma responsabilidade, uma vez que é necessário compreender nossas limitações e o seu sentido positivo, percebendo que:

[c]ada ser humano nasce com um determinado, vastíssimo, conjunto de possibilidades próprias, possibilidades que instituem e marcam limites, estes entendidos na sua ambivalência negativa, mas, também e fundamentalmente, positiva: estes limites mostram exactamente aquilo que um ser humano pode fazer, não apenas o que não pode fazer, mas, sobretudo, o que pode fazer, absolutamente. Os limites são a marca metafísica de nossa mesma positividade ontológica. O que os transcende é o que não é precisamente nosso. O que é precisamente não-nosso. Assim, os nossos limites, na substância do que constitui o acto próprio de cada um de nós, são a nossa riqueza, não a nossa miséria. ${ }^{47}$

Há, assim, fins subjetivos a mim impostos pela minha condição humana; porém, há fins subjetivos a mim dispostos, alargados pela vida plural. Isto é: a causalidade que me é possível, sozinho, alcançar, deve ser combinada com outro tipo de causalidade, de um círculo maior, disposto a mim porque estou com os outros.

Repensam-se e redefinem-se, assim justiça e interesse público. Para quem leve essa perspectiva em consideração, pode-se entender, com Ricardo Timm de Souza ${ }^{48}$, que “[...] justiça é a articulação entre a ética e a política de tal modo que a alteridade do outro humano e da natureza seja preservada e promovida através de atos e relações concretos." E se pode entender o interesse público como “[...] o interesse de todos nós em ver realizado o maior empreendimento de cada um de nós." 49

É importante que o Estado e as instituições exerçam um papel multiplicador desse segundo tipo de causalidade (aquela do círculo maior que se abre na imbricação entre o "todos nós" com o "cada um de nós"), fomentando uma cultura de comumnidade. Mas as ações estatais não substituem a horizontalidade natural das ações das pessoas no sentido da evolução do Estado e, pois, do desenvolvimento humano.

\section{Interesse Público como Critério para o Desenvolvimento Humano: 0 desenho de uma métrica alternativa}

Em relação à seção anterior, percebe-se que uma abordagem abrangente do interesse público leva a linha de investigação na direção do desenvolvimento, sendo natural aproximar essa investigação à interpretação econômica (lugar histórico da análise do desenvolvimento). Porém, deve-se entender que uma tal interpretação ganhará importância não nas versões da Economia clássica, que estudam o desenvolvimento estritamente econômico, mas nas suas versões contemporâneas, onde se abre o campo de pesquisa para o desenvolvimento humano, inclusive a partir de abordagens de outras naturezas, como jurídicas, sociais e culturais. Em inspiração kantiana para os termos, a análise do preço (ou, dito de modo mais específico, dos fenômenos) é substituída pela análise do valor (ou, dito de modo mais específico, das pessoas). Ao tratarmos de Economia, visa-se, particularmente, à chamada Abordagem das Capacitações, um enfrentamento para o qual o grande desafio parece-nos de ordem eminentemente prática: de um lado, criar uma econométrica

\footnotetext{
PEREIRA, Maria Helena da Rocha. Da ontologia da "polis" em Platão. 2011. p. 30-1. Disponível em: http://www.lusosofia.net/ textos/pereira_americo_ontologia_da_polis_em_platao.pdf. Acesso em: 15 dez. 2019.

48 SOUZA, Ricardo Timm de. Ética como fundamento: uma introdução à ética contemporânea. São Leopoldo: Nova Harmonia, 2004. p. 72 .

49 HAEBERLIN, Mártin. Uma teoria do interesse público: fundamentos do estado meritocrático de direito. Porto Alegre: Livraria do Advogado, 2017. p. 303.
} 
adequada de valores humanos; de outro, prover um entendimento mais contundente sobre como melhor alcançar esses valores.

É mesmo tarefa desafiadora criar métricas sólidas para os intangíveis valores da pessoa humana ${ }^{50}$, com o intuito de melhor entender o desenvolvimento humano e as atividades estatais que produzam esse desenvolvimento. Esse resultado foi, de fato, produzido pela mais conhecida das métricas, o Índice de Desenvolvimento Humano (IDH), adotado pelo Programa das Nações Unidas para o Desenvolvimento (PNUD) em 1990, ao lado do qual vem-se agregando índices alternativos e complementares (a exemplo do Equality Ranking, do Human Freedom, do Freedom House Index, do Prosperity Index, do Social Progress Index, do Happy Planet Index, entre outros) cuja função de contribuir para a correção de distorções do modelo proposto pelo IDH, especialmente para identificação do impacto da pobreza e das desigualdades no desenvolvimento, foi apontada por Feitosa e Silva. ${ }^{51}$ Acreditamos, porém, que essas métricas costumam não levar em consideração um importante critério para a definição do desenvolvimento: o interesse público.

É necessário, nesse sentido, alargar a definição atual de desenvolvimento humano. Em sua forma clássica, conforme aparece interpretada por Fukuda-Parr e Kumar ${ }^{52}$, ele é “[...] uma expansão das capacitações humanas, uma extensão de escolhas, um realce das liberdades e uma satisfação de direitos humanos." O Programa das Nações Unidas para o Desenvolvimento vai na mesma direção:

O desenvolvimento humano é a expansão da liberdade de as pessoas viverem vidas mais longas, saudáveis e criativas; de avançarem em outros objetivos que elas tenham razões para valorizar; e de se engajar ativamente em moldar um desenvolvimento com vistas à igualdade e à sustentabilidade em um planeta compartilhado. ${ }^{53}$

$\mathrm{Na}$ forma colocada, essa definição, repetida ad nauseam nos relatórios de desenvolvimento humano, comporta o seu significado carente de uma reflexão adequada sobre a importância da comumnidade (e, por consequência, do interesse público) para alcançar o desenvolvimento humano. Os indivíduos devem ser vistos como autônomos (como fins em si mesmos), mas, ao mesmo tempo, como capazes do exercício de razão pública e de emoções públicas. Desenvolvimento humano, assim como o interesse público, relaciona-se, também, ao tratar todos e cada um de nós como igual a nós.

Esse acréscimo (da comumnidade) à noção corrente de desenvolvimento humano deve aparecer na sua definição. Em uma métrica adequada, portanto, o interesse público há de constar como um critério, evoluindo-se a concepção usual.

A fim de demonstrar tal acréscimo, sugere-se um entendimento da noção de interesse público na perspectiva do desenvolvimento humano em três diferentes níveis, abaixo sintetizados. No terceiro e último nível, desenha-se uma métrica alternativa, que leva o interesse público à condição de critério para o desenvolvimento.

\subsection{Primeiro Nível: as ações governamentais}

O primeiro nível do interesse público na perspectiva do desenvolvimento humano é aquele relacionado às ações governamentais. Nele, presta-se atenção em quanto os governos alocam de seus orçamentos em

\footnotetext{
50 Sobre essa problemática, vide SUNSTEIN, Cass. Valuing life: humanizing the regulatory state. Chicago: University of Chicago Press, 2014. (especialmente capítulos 3 a 5)

51 FEITOSA, Maria Luiza Mayer; SILVA, Paulo Henrique Tavares da. Indicadores de desenvolvimento humano e efetivação de direitos humanos: da acumulação de riquezas à redução da pobreza. Revista de Direitos e Garantias Fundamentais, Vitória, n. 11, jan./ jun. 2012, passim.

52 FUKUDA-PARR, Sakiko; KUMAR, A. K. Shiva. Readings in human development. concepts, measures and policies for a development paradigm. Oxford: Oxford University Press, 2003. p. xxi.

53 UNITED NATIONS DEVELOPMENT PROGRAMME. Human development report 2010: the real wealth of nations: pathways to human development. New York: Palgrave Macmillan, 2010. p. 2.
} 
saúde, em educação e em outros bens públicos, assim como na forma que esses bens são distribuídos entre diferentes grupos da sociedade. Também interessa, nesse nível, saber se os governos garantem certos direitos às pessoas de acordo com suas respectivas legislações. Uma vez que esse nível é inspirado na ideia de "bens primários" ("primary goods"), pode-se o entender como a aproximação rawlsiana do tema.

É comum entender o interesse público considerando-se o que os governos fazem, o que não é algo trivial, especialmente a respeito do fato de que eles devem usar o poder equilibrando grupos distintos. Desse equilíbrio surgirá um aguardado resultado de prioridades políticas, potencialmente mais agradável a uns que a outros. A questão, nesses casos, é entender o nível de interesse público no estabelecimento dessas prioridades e, em consequência, nas ações governamentais.

Consideremos, para demonstração, a Tabela 1, que enfoca despesas em saúde e educação pública para alguns países da América Latina, dados relacionados, essencialmente, a esse primeiro nível de interesse público. 


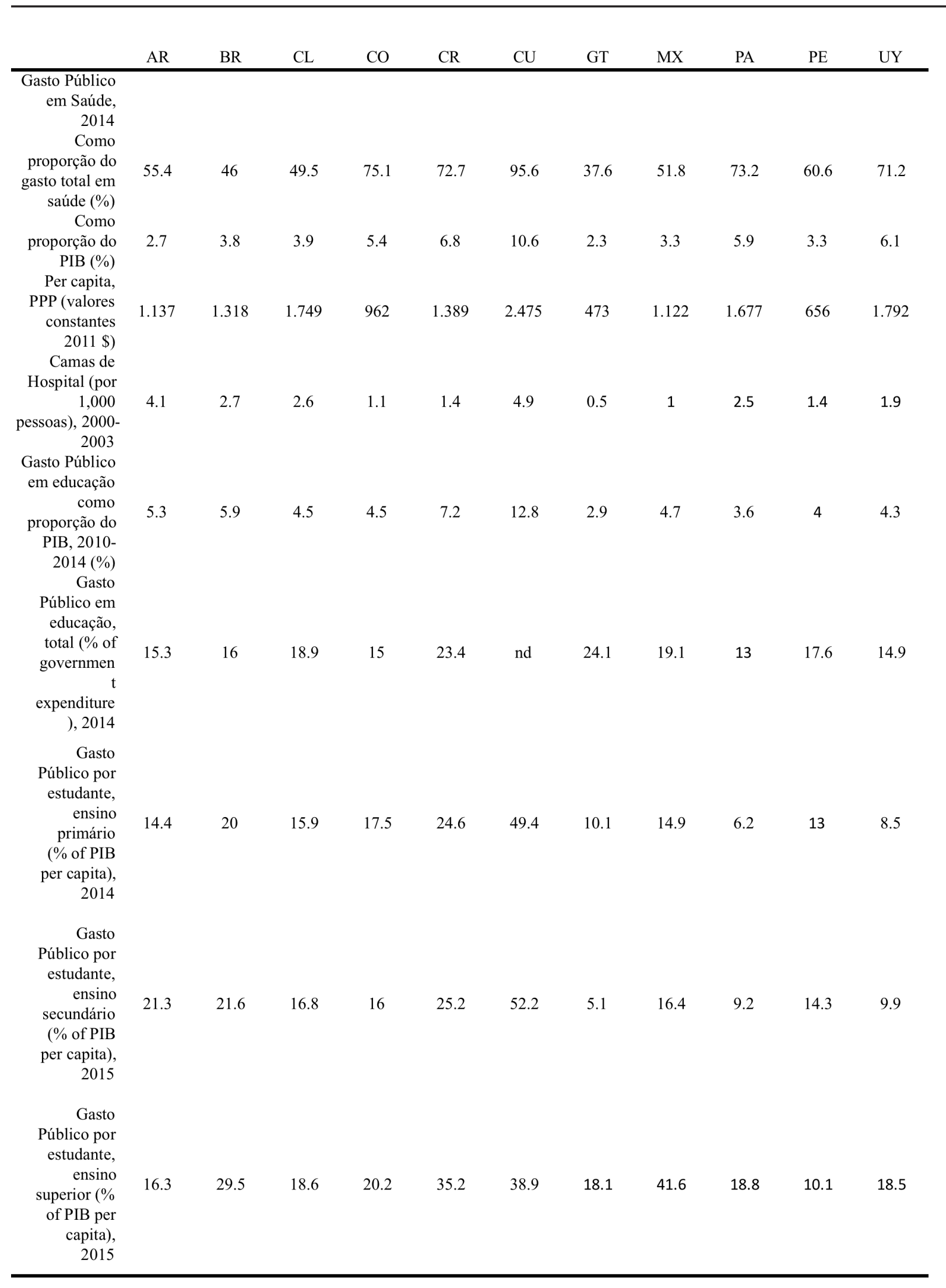

Fonte: World Development Indicators (http://data.worldbank.org/products/wdi). 
A tabela demonstra, como regra, que países como Uruguai, Cuba ${ }^{54}$ e Costa Rica gastam mais da sua renda em bens públicos como saúde e educação. Podemos ver também como esses gastos são desiguais entre níveis distintos de ensino, com um gasto proporcionalmente maior per capita no ensino terciário do que no primário, o que pode ser interpretado como uma prioridade de investimento nas elites em relação a outros grupos sociais. Deve-se enfatizar, mais uma vez, que esta é uma medida de alocação de recursos públicos, que pode ser um bom indicador do balanceamento entre o poder e as prioridades políticas; contudo, ela diz pouco sobre como essa alocação afeta no efetivo bem-estar das sociedades.

\subsection{Segundo Nível: o impacto das ações governamentais}

O segundo nível do interesse público na perspectiva do desenvolvimento humano é aquele relacionado ao impacto das ações governamentais na autonomia das pessoas. Esse é o campo tradicional das estatísticas de desenvolvimento humano, notadamente o Índice de Desenvolvimento Humano (IDH).$^{55}$ Com base em críticas endereçadas à Teoria da Justiça, de John Rawls - especialmente por escritos de Amartya Sen —, de que a alocação de recursos é um indicador imperfeito do bem-estar humano, esse nível enfoca os impactos do provimento de bens públicos. Sua intenção é entender como as capacitações são distribuídas entre os indivíduos em uma determinada sociedade. Uma vez que esse segundo nível reflete o modo tradicional do entendimento sobre o desenvolvimento humano, ele pode ser entendido como a aproximação seniana do tema.

O interesse público também diz respeito à eficiência e à responsabilidade no provimento de bens públicos. Há uma longa lista de problemas que podem afetar a relação estreita entre a alocação de recursos para esse provimento e a sua efetiva entrega. Estão na lista: corrupção, paternalismo, ineficiência administrativa, falta de transparência, responsabilidade fiscal e planejamento, dentre outros. Nesse nível, busca-se suprimir esses problemas para que os governos modifiquem, de fato, o bem-estar de suas populações.

Considerando-se os dados da Tabela 2 (afetos a esse segundo nível de interesse público na comparação entre esses países), percebe-se diferença de 0.2 pontos no IDH entre o melhor país ordenado, Chile, e o pior, Guatemala. Isso pode ser verificado concretamente em diferenças como expectativa de vida ao nascer (quase 10 anos), populações sem acesso a saneamento (35\% de disparidade) e maior subnutrição infantil na Guatemala (44.7\%).

\begin{tabular}{|c|c|c|c|c|c|c|c|c|c|c|c|}
\hline & AR & BR & CL & $\mathrm{CO}$ & CR & $\mathrm{CU}$ & GT & MX & PA & PE & UY \\
\hline $\begin{array}{l}\text { PIB per } \\
\text { capita, PPP } \\
\text { (constante } \\
2011 \\
\text { internacional } \\
\$), 2015\end{array}$ & 20.945 & 14.145 & 21.665 & 12.762 & 14.006 & 7.455 & 7.063 & 16.383 & 19.470 & 11.295 & 19.148 \\
\hline $\begin{array}{l}\text { Índice de } \\
\text { Desenvolvime } \\
\text { nto Humano, } \\
2016\end{array}$ & 0.827 & 0.754 & 0.847 & 0.727 & 0.776 & 0.775 & 0.640 & 0.762 & 0.788 & 0.740 & 0.795 \\
\hline
\end{tabular}

\footnotetext{
54 Embora Cuba tenho sido acrescentada nas tabelas para efeitos de comparação — considerando possuir níveis acima da média na América Latina para as métricas nos três níveis aqui desenhados —, vale reforçar que a democracia é um pressuposto de ambas as abordagens que construímos para o interesse público.

55 Uma relação entre interesse público e IDH pode ser encontrada em PAMPLONA, Leandro. Boa administração, interesse público e índice de desenvolvimento humano. Interesse Público, Belo Horizonte, ano 13, n. 67, p. 187-201, maio/jun. 2011.
} 


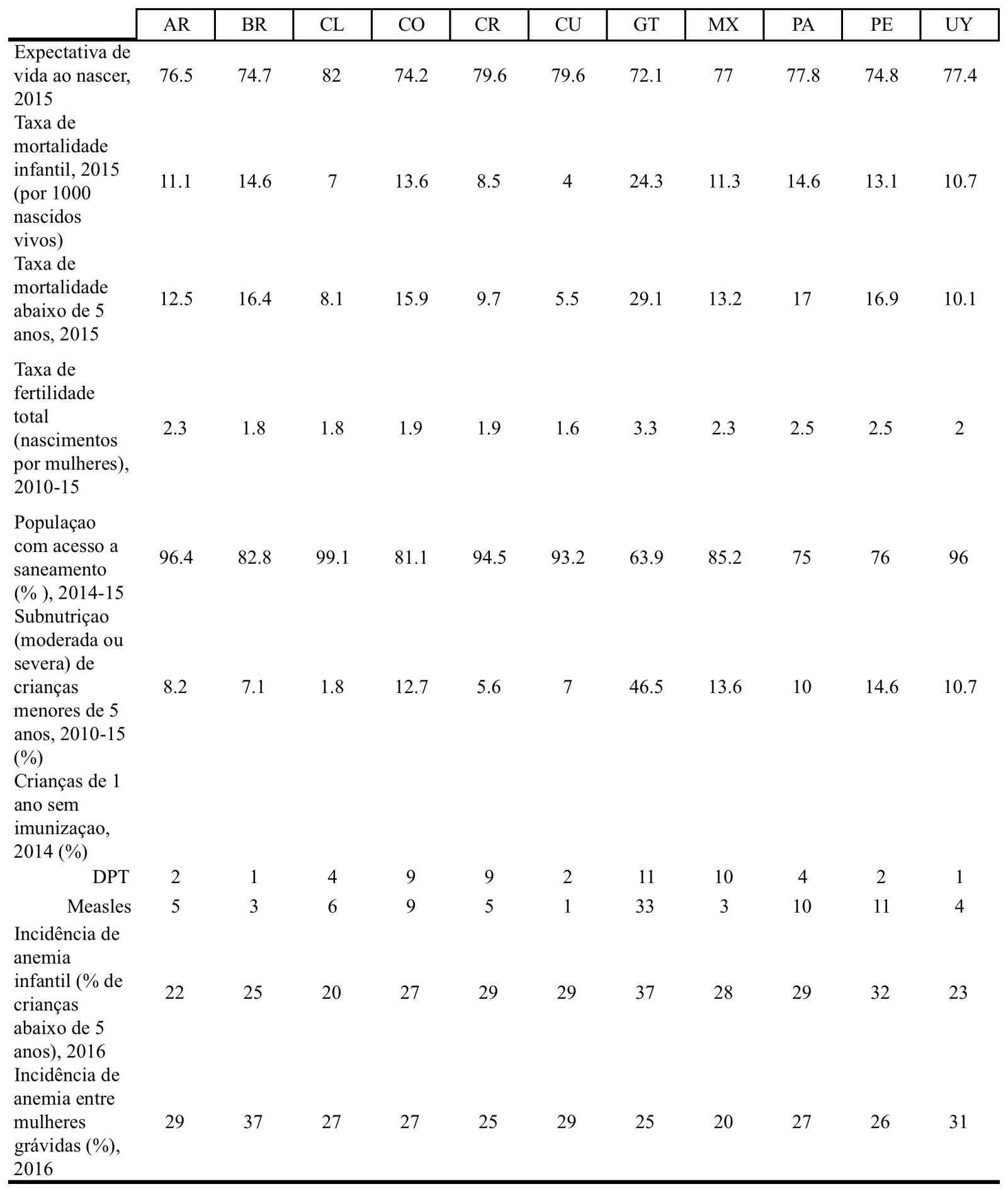




\begin{tabular}{|c|c|c|c|c|c|c|c|c|c|c|c|}
\hline & AR & $\mathrm{BR}$ & CL & $\mathrm{CO}$ & $\mathrm{CR}$ & $\mathrm{CU}$ & GT & MX & $\mathrm{PA}$ & $\mathrm{PE}$ & UY \\
\hline $\begin{array}{l}\text { Anos médios } \\
\text { de } \\
\text { escolaridade, } \\
\text { idade } 25+, \\
2015 \\
\text { Taxa de } \\
\text { alfabetizaçao, } \\
15-24 \text { anos, } \\
2010-2016 \\
(\%)\end{array}$ & 9.9 & 7.8 & 9.9 & 7.6 & 8.7 & 11.8 & 6.3 & 8.6 & 9.9 & 9 & 8.6 \\
\hline $\mathrm{M}$ & 99.1 & 98.4 & 99 & 98.1 & 99 & 99.8 & 95.5 & 98.9 & 98 & 99.1 & 98.6 \\
\hline $\mathrm{F}$ & 99.5 & 99.2 & 99.1 & 98.9 & 99.2 & 99.9 & 93.3 & 99 & 97.3 & 98.7 & 99.2 \\
\hline $\begin{array}{l}\text { Taxa de } \\
\text { Alfabetizaçao } \\
\text { adultos, }(\% \\
\text { acima de } 15 \\
\text { anos) } 2010- \\
2016\end{array}$ & & & & & & & & & & & \\
\hline $\mathrm{M}$ & 98.04 & 91.4 & 96.4 & 94.1 & 97.3 & 99.7 & 86.7 & 95.5 & 94.7 & 97.2 & 98.2 \\
\hline $\mathrm{F}$ & 98.1 & 92.1 & 96.2 & 94.4 & 97.5 & 99.8 & 76.4 & 93.5 & 93.5 & 91.2 & 98.9 \\
\hline $\begin{array}{l}\text { Programme } \\
\text { for } \\
\text { International } \\
\text { Student } \\
\text { Assessment } \\
\text { (PISA), 2015 }\end{array}$ & & & & & & & & & & & \\
\hline Matemática & 409 & 377 & 423 & 391 & 400 & nd & nd & 408 & nd & 387 & 418 \\
\hline Literatura & 425 & 407 & 459 & 425 & 427 & nd & nd & 423 & nd & 398 & 437 \\
\hline Ciência & 432 & 401 & 447 & 416 & 420 & nd & nd & 416 & nd & 397 & 435 \\
\hline $\begin{array}{l}\text { Reprovaçoes, } \\
\text { ensino } \\
\text { primário, total } \\
\text { (\% matrículas } \\
\text { totais), } 2015 \\
\text { Incidência de } \\
\text { pobreza US\$ } \\
3.20 \text { por dia } \\
\text { (PPP) (\% da } \\
\text { populaçao), } \\
2014-2015\end{array}$ & 4.5 & 9.3 & 3.1 & 13.1 & 4.2 & 0.6 & 25.3 & 11.8 & 2.6 & 3.2 & 4.6 \\
\hline $\begin{array}{l}\text { Parcela da } \\
\text { renda dos } 20 \% \\
\text { mais pobres, } \\
2014-15\end{array}$ & 4.8 & 3.6 & 4.8 & 3.6 & 4.3 & nd & 4.4 & 5.1 & 3.5 & 4.6 & 5.1 \\
\hline $\begin{array}{l}\text { Parcela da } \\
\text { renda dos } 20 \% \\
\text { mais ricos, } \\
2014-15\end{array}$ & 30.8 & 40.5 & 38 & 44.5 & 36.7 & nd & 38.4 & 39.7 & 39.3 & 33.4 & 30.8 \\
\hline
\end{tabular}

Fonte: World Development Indicators (http://data.worldbank.org/products/wdi), Human Development Report (2013) e UNICEF (2014).

É possível, também, ver os resultados das prioridades dos países em termos de taxa de imunização infantil e incidência de anemia entre crianças e mulheres. Quando comparamos os anos médios de escolaridade entre os países, vemos com clareza como a educação está longe de ser uma prioridade no Brasil e o resultado histórico 
disso é que seus adultos, com mais de 25 anos, têm em média apenas 7,8 anos de estudo (ganhando apenas da Colômbia e Guatemala). Vale a pena enfatizar que, enquanto o primeiro nível de interesse público reflete apenas a dimensão dos recursos, o segundo foca nos resultados que esses recursos são capazes de gerar.

\subsection{Terceiro Nível: o “desenvolvimento como comumnidade”}

O terceiro nível do interesse público na perspectiva do desenvolvimento humano é aquele relacionado a como as pessoas tratam umas às outras e como as instituições interferem nesse tratamento. Para além do elemento justificador da razão pública, fala-se aqui em aspectos motivacionais relacionados à comumnidade. Pode-se encontrar esse nível em alguns comportamentos da sociedade civil (incluindo homicídios e acidentes de trânsito), e também em políticas públicas, como aquelas relacionadas à arquitetura dos espaços públicos e da promoção da cultura popular. Tem-se, nesse nível, a expectativa de que, nas sociedades onde há uma preocupação com os seus indivíduos, serão desenvolvidas leis e instituições que darão forma a sentimentos como proteção, compaixão e equidade de uns para com os outros, assim como a própria sociedade civil encarregar-se-á de prover bens públicos. Esse terceiro nível, por associado ao trabalho de Martha Nussbaum $^{56}$, pode ser entendido como a aproximação nussbaumniana do tema.

Enquanto Rawls, ao tratar da "razão pública", foca em princípios constitucionais, Martha Nussbaum ${ }^{57}$ preocupa-se com a lista de capacitações fundantes desses princípios — nos termos que aqui expomos, poder-se-ia dizer, pré-constitucionais — e em como os governos podem realizar, proativamente, a promoção de "emoções públicas". A natureza institucional das emoções públicas pode ser vista não apenas a partir do provimento de bens públicos, mas em como as sociedades revelam seus valores compartilhados de igual respeito, afeto ou mesmo compaixão e altruísmo em suas vidas cotidianas. O desenvolvimento (e sua medida) deve ser sobre as pessoas entendendo as pessoas não como meios para seus interesses pessoais, mas como fins em si mesmas.

É difícil encontrar variáveis para demonstrar sentimentos, emoções públicas e o modo como as pessoas tratam umas às outras. Em termos gerais, porém, alguns indicadores podem ser usados, como aqueles que aparecem na Tabela 3: taxas de homicídio, acidentes automobilísticos fatais (especialmente com pedestres), população carcerária e o nível de desigualdade econômica.

56 NUSSBAUM, Martha. Political emotions: why love matters for justice. Cambridge: The Belnak Press of Harvard University Press, 2013.

57 NUSSBAUM, Martha. Frontiers of justice: disability, nationality, species membership. Cambridge: The Belnak Press of Harvard University Press, 2006. p. 222. 


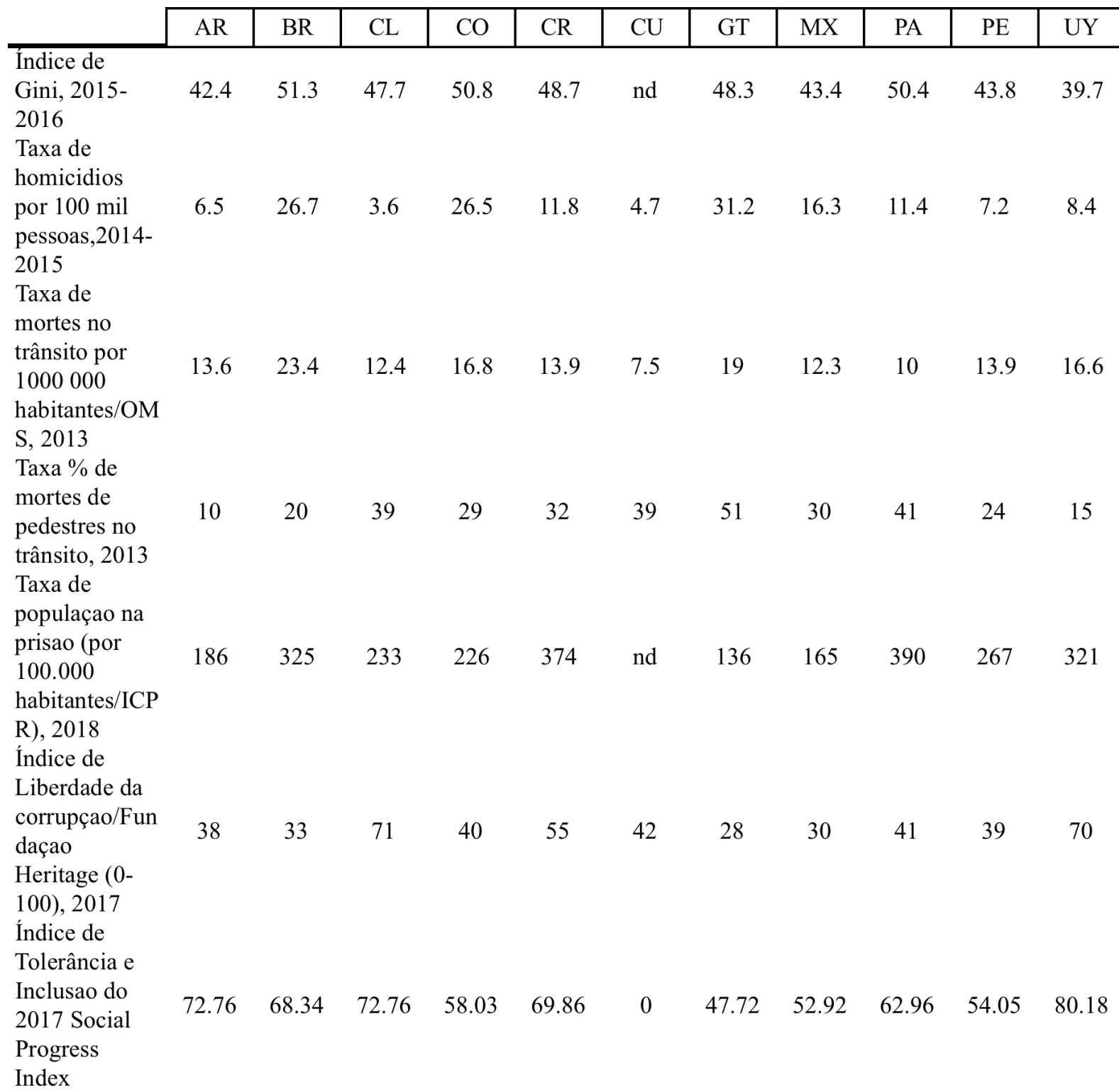

Fonte: Heritage Foundation (http://www.heritage.org), World Development Indicators (http://data.worldbank. org/products/wdi).

Utilizando esses dados, percebe-se que as sociedades latino-americanas possuem, em média, não somente alto nível de desigualdade econômica, mas também de outras formas de desigualdade que se manifestam em indicadores de quebra de uma harmonia básica social, como por exemplo o que trata de uma alta proporção de homicídios, notadamente no Brasil, Colômbia e Guatemala, o que sugere baixo nível de desenvolvimento como comumnidade, considerando-se a facilidade com que as pessoas matam umas às outras. Também a falta de uma estrutura institucional que fomente a tolerância e inclusão em vários desses países pode ser vista como tendência de manutenção de um conflito político que pode se manifestar em corrupção e criminalidade. Isso é bastante sugestivo, também, de um baixo índice de interesse público considerando este terceiro e necessário nível de seu entendimento.

Embora o objetivo deste texto não seja fornecer um índice pleno para indicar o "desenvolvimento como comumnidade", na tentativa de ilustração da questão sob uma perspectiva de desenvolvimento humano, pode-se pensar no desenho de uma métrica que considere os três níveis de interesse público, a partir dos 
parâmetros expostos.

Tomando-se dados como gastos com saúde em proporção do PIB (como representativo do primeiro nível), a taxa de mortalidade antes dos cinco anos e reprovações no ensino primário (como representativo do segundo nível) e a taxa de homicídios por 100.000 habitantes (como representativo do terceiro nível), chegar-se-ia - normalizando as variáveis, harmonizando-as para que estejam todas indicando números maiores para um grau de interesse público maior e usando uma média aritmética para agregá-las —, em um resultado como o apresentado no Gráfico 1, elaborado pelos autores.

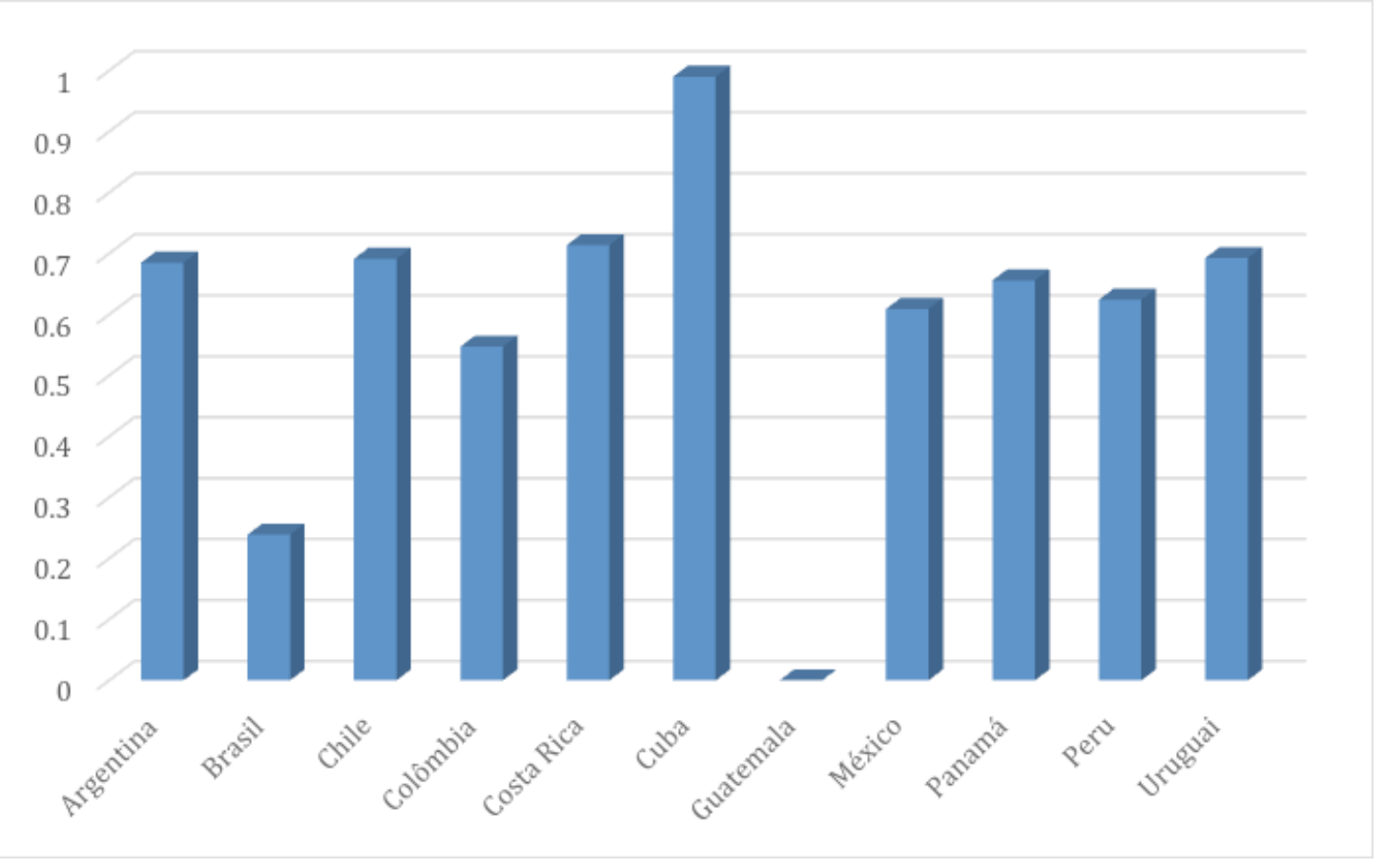

Os resultados apontam que o grau de interesse público aferido nesse conjunto de países é maior em Cuba, seguido de Costa Rica, Uruguai, Chile e Argentina. No outro extremo, encontramos com baixo grau de interesse público o Brasil e a Guatemala.

Um índice como o exposto não apresenta uma proposta definitiva, mas vale para o efeito de nos imbuir com diferentes percepções sobre o interesse público enquanto critério de desenvolvimento humano. E sobre como diferentes Estados (e suas sociedades) têm lidado com o seu substrato mais elementar: as pessoas.

\section{Considerações finais}

O interesse público constitui o Estado. É o fundamento que une as pessoas a um governo comum, compreendendo aquilo que podemos chamar comumnidade: um senso de vida em comum sustentado em valores coletivos e relacionado a um plexo de sentimentos morais que fazem parte da estrutura das sociedades.

Podem-se realizar duas abordagens sobre o interesse público: uma abordagem estrita, em que o interesse público é apenas um desenvolvimento jurídico, relacionado à realização de direitos e liberdades básicas; e uma abordagem abrangente, na qual se acresce a esse desenvolvimento jurídico a perspectiva do desenvolvimento humano, aproximando o Direito à Economia do Desenvolvimento, especialmente a partir da fundação conceitual elementar da chamada Abordagem das Capacitações. 
Este texto desloca o eixo do interesse público da comunidade jurídica para essa comunidade em sentido abrangente. Ou, em última análise, para esse conceito de comumnidade, ao demonstrar que o interesse público é um importante ingrediente para o desenvolvimento humano. Nessa visão de prosperidade (desenvolvimento), ver o outro no exercício de sua realização importa tanto quanto a eficácia do catálogo de direitos e liberdades a ele disposto, inclusive porque aquela realização é condição dessa eficácia.

Se, em nível micro, o interesse público tem a ver com o igual respeito, o afeto e comportamento tolerante que uns cidadãos oferecem aos outros, em nível macro ele refere-se às prioridades dos governos e do impacto distributivo e eficiente de uma grande gama de políticas públicas. De tal modo, importam as ações do Estado (sendo desejável aproximar o nexo de causalidade entre elas e a sua efetiva contribuição para a emancipação das pessoas) e importam as ações das pessoas (sendo desejável também que essas, sentindo-se responsáveis por si e pelos outros, busquem causalidade àquilo que é construído em sua volta). Estado, instituições e pessoas devem exercer um papel multiplicador na expansão do círculo que imbrica o "todos nós" com o "cada um de nós".

Este artigo sugere um entendimento da noção de interesse público na perspectiva do desenvolvimento humano, assim, em três diferentes níveis: o das ações governamentais (ligado ao uso dos recursos públicos); o do impacto das ações governamentais (ligado ao resultado entregue no uso dos recursos em favor das capacidades humanas); e o do "desenvolvimento como comumnidade" (ligado ao modo como as pessoas tratam umas às outras). Ao fim, percebe-se que todos esses níveis importam para o desenvolvimento humano, deixando-se exposta a conclusão de que, em uma métrica adequada que evolua de sua concepção usual, o desenvolvimento humano deve ter o interesse público também como um critério. Dito de outro modo: a comumnidade é uma importante dimensão do desenvolvimento, a qual, por não pode ser deixada de lado, deve aparecer em suas equações.

Porquanto não há concepção de ser senão a de ser com os outros, evoca-se um desenho de uma métrica, na qual o interesse público é levado, especificamente, em consideração. Se sua incipiência ainda não lhe fizer um indicador adequado do interesse público como critério do desenvolvimento humano, lança ele, ao menos, um importante instrumento de debate na comunidade acadêmica e em geral sobre o quanto nós estamos prestando atenção naquilo que, em última análise, deveria estar gravado no cristal atômico das sociedades: a contribuição do todo para o cada um; e do cada um para o todo.

\section{Referências}

ANDERHEIDEN, Michael. Gemeinwobl in republik und union. Tübingen: Mohr Siebeck, 2006.

ANDERHEIDEN, Michael. Ökonomik, gemeinwohl und verfassungsrecht. In: BUNGENBERG, Marc (org.). Recht und ökonomik. München: C.H. Beck, 2004

BARCELlOS, Ana Paula de. Políticas públicas e o dever de monitoramento: "levando os direitos a sério". Revista Brasileira de Políticas Públicas, Brasilia, v. 8, n. 2, p. 251-265, ago. 2018.

BATISTA JUNIOR, Onofre Alves. O estado democrático de direito pós-providência brasileiro em busca da eficiência pública e de uma administração pública mais democrática. Revista Brasileira de Estudos Políticos, Belo Horizonte, v. 98, p. 119-158, 2008.

BLANKART, Charles. Gemeinwohl durch direkte und repräsentative Demokratie. In: ARNIM, Hans Herbert von; SOMMERMANN, Karl-Peter (org.). Gemeinwoblgefährdung und gemeinwoblsicherung: vorträge und diskussionsbeiträge auf der 71: staatswissenschaftlichen fortbildungstatung. Berlin: Duncker \& Humboldt, 2004.

BONAVIDES, Paulo. Curso de direito constitucional. 14. ed. São Paulo: Malheiros, 2004. 
BREUS, Thiago Lima. Políticas públicas no estado constitucional: problemática da concretização dos direitos fundamentais pela administração pública brasileira contemporânea. Belo Horizonte: Fórum, 2007.

BUBER, Martin. Ich und du. Stuttgart: Philip Reclam, 1995.

CALLIESS, Christian. Gemeinwohl in der Europäischen Union: Über den staaten-und verfassungsverbund zum gemeinwohlverbund. In: BRUGGER, Winfried; KIRSTE, Stephan; ANDERHEIDEN, Michael (org.). Gemeinwohl in Deutschland, Europa und der Welt. Interdisziplinäre Studien zи Recht und Staat, Baden-Baden, n. 24, 2002.

CAPRA, Fritjof. A teia da vida: uma nova compreensão científica dos sistemas vivos. Tradução Newton Roberval Eichemberg. São Paulo: Cultrix, 1996.

CARVALHO FILHO, José dos Santos. Interesse público: verdades e sofismas. In: DI PIETRO, Maria Sylvia Zanella; RIBEIRO, Carlos Vinícius Alves (org.). Supremacia do interesse público e outros temas relevantes do direito administrativo. São Paulo: Atlas, 2010.

COMIM, Flávio Vasconcellos. Publicness and human development. In: 2015 HUMAN DEVELOPMENT AND CAPABILITY ASSOCIATION CONFERENCE, 2015, Washington. Proceedings...Washington: Georgetown University, 2015.

COULANGES, Fustel de. La cité antique. Paris: Librairie Hachette, 1900.

DEWEY, John. Liberalism and social action. New York: Prometheus Book, 2000.

DI PIETRO, Maria Sylvia Zanella. O Princípio da Supremacia do Interesse Público: sobrevivência diante dos ideais do neoliberalismo. In: DI PIETRO, Maria Sylvia Zanella; RIBEIRO, Carlos Vinícius Alves (org.). Supremacia do interesse público e outros temas relevantes do direito administrativo. São Paulo: Atlas, 2010.

DWORKIN, Ronald. A matter of principle. New York: Oxford University Press, 1985.

DWORKIN, Ronald. Unenumerated rights: wheter and how roe should be overruled. The University of Chicago Law Review, Chicago, v. 59, n. 1, p. 381-432, 1992.

ENGEL, Christoph; ROCKENBACH, Betinna. We are not alone: the impact of externalities on public good provision. 2011. Disponível em: http://ssrn.com/abstract=1463259. Acesso em: 15 dez. 2019

FEITOSA, Maria Luiza Mayer; SILVA, Paulo Henrique Tavares da. Indicadores de desenvolvimento humano e efetivação de direitos humanos: da acumulação de riquezas à redução da pobreza. Revista de Direitos e Garantias Fundamentais, Vitória, n. 11, p. 119-147, jan./jun. 2012.

FOUCAULT, Michel. Omnes et singulatim: vers une critique de la raison politique. 1994. p. 134-161. Disponível em: http://www.cip-idf.org/article.php3?id_article=4031. Acesso em: 15 dez. 2019.

FREITAS, Juarez. Discricionariedade administrativa e o direito fundamental à boa administração pública. 2. ed. São Paulo: Malheiros, 2009.

FREITAS, Juarez. Sustentabilidade: direito ao futuro. Belo Horizonte: Fórum, 2011.

FUKUDA-PARR, Sakiko; KUMAR, A. K. Shiva. Readings in human development: concepts, measures and policies for a development paradigm. Oxford: Oxford University Press, 2003.

HÄEBERLE, Peter. Öffentliches interesse als juristisches problem: eine analyse von gesetzgebung und rechtsprechung. Berlin: Berliner Wissenschafts-Verlag, 1970.

HAEBERLIN, Mártin. Uma teoria do interesse público: fundamentos do estado meritocrático de direito. Porto Alegre: Livraria do Advogado, 2017. 
HAQ, Mahbub ul. Reflections on human development. Delhi: Oxford University Press, 1999.

HELLER, Hermann. The Nature and Structure of the State. In: Cardozo Law Review, New York, v. 18, n. 1, p. 1139-1116, set. 1996.

JELLINEK, Georg. Allgemeine staatslehre. 3. ed. Berlin: O. Häring, 2014.

JONAS, Hans. O princípio responsabilidade: ensaio de uma ética para a civilização tecnológica. Tradução de Marijiane Lisboa e Luiz Barros Montez. Rio de Janeiro: Contraponto, PUC-Rio, 2010.

LEUPRECHT, Peter. Idéologie pan-économique et bien commun. In: DELAS, Olivier; DEBLOCK, Christian (org.). Le bien commun comme réponse politique à la mondialisation. Bruxelles: Bruylant, 2003.

LOEWENSTEIN, Karl. Verfassungslehre. Tradução de Rüdiger Boerner. Tübingen: Mohr Siebeck, 1959.

MACINTYRE, Alasdair. After virtue: a study in moral philosophy. 3. ed. Notre Dame: University of Notre Dame, 2007.

NUSSBAUM, Martha. Frontiers of justice: disability, nationality, species membership. Cambridge: The Belnak Press of Harvard University Press, 2006.

NUSSBAUM, Martha. Creating capabilities: the human development approach. Cambridge: The Belnak Press of Harvard University Press, 2011.

NUSSBAUM, Martha. Political emotions: why love matters for justice. Cambridge: The Belnak Press of Harvard University Press, 2013.

PAMPLONA, Leandro. Boa administração, interesse público e índice de desenvolvimento humano. Interesse Público, Belo Horizonte, ano 13, n. 67, p. 187-201, maio/jun. 2011.

PEREIRA, Maria Helena da Rocha. Da ontologia da "polis" em Platão. 2011. Disponível em: http://www.lusosofia.net/textos/pereira_americo_ontologia_da_polis_em_platao.pdf. Acesso em: 15 dez. 2019.

PIGOU, Arthur. The economics of welfare. 4. ed. London: Transaction, 2002.

SANDEL, Michael. Justice: what's the right thing to do? New York: Farrar, Straus and Giroux, 2010.

SARLET, Ingo Wolfgang. Teoria Geral dos Direitos Fundamentais. In: SARLET, Ingo Wolfgang; MARINONI, Luiz Guilherme; MITIDIERO, Daniel. Curso de direito constitucional. 3. ed. São Paulo: Revista dos Tribunais, 2014.

SEN, Amartya. On ethics and economics. Gateshead: Blackwell, 1988.

SEN, Amartya. Development as freedom. Oxford: Oxford University Press, 1999.

SEN, Amartya. The idea of justice. Cambridge: Harvard University Press, 2009.

SOUZA, Ricardo Timm de. Ética como fundamento: uma introdução à ética contemporânea. São Leopoldo: Nova Harmonia, 2004.

STREETEN, Paul Patrick. Thinking about development. Cambridge: Cambridge University Press, 1995.

SCHWEIZ. [Bundesverfassung (1999)]. Bundesverfassung der Schweizerischen Eidgenossenschaft. Disponível em: http://www.admin.ch/opc/de/classified-compilation/19995395/index.html\#a8. Acesso em: 15 dez. 2019.

SUNSTEIN, Cass. Valuing life: humanizing the regulatory state. Chicago: University of Chicago Press, 2014.

UERPMANN, Robert. Das öffentliche interesse: seine bedeutung als tatbestandsmerkmal und als dogmatischer begriff. Tübingen: Mohr Siebeck, 1999. 
UNITED NATIONS DEVELOPMENT PROGRAMME. Human development report 2010: the real wealth of nations: pathways to human development. New York: Palgrave Macmillan, 2010.

UNGER, Roberto Mangabeira. The left alternative. London: Verso, 2009.

VERNES, Monique. Les illusions endémiques du bien commum. Concept opératoire ou formule rhétorique? In: DELAS, Olivier; DEBLOCK, Christian (org.). Le bien commun comme réponse politique à la mondialisation. Bruxelles: Bruylant, 2003. 
Para publicar na revista Brasileira de Políticas Públicas, acesse o endereço eletrônico www.rbpp.uniceub.br

Observe as normas de publicação, para facilitar e agilizar o trabalho de edição. 